\title{
Analysis of Human Capital Level and Inequality Interrelation
}

\author{
Larionova N.I.a \\ Varlamova J.A.b \\ a b Kazan Federal University, Institute of Management, Economics and Finance, Kazan, 420008, Russia \\ Email: Julia.Varlamova@kpfu.ru.
}

\section{Doi:10.5901/mjss.2015.v6n1s3p252}

\begin{abstract}
This article presents the results of the relationship between human capital and inequality in income distribution in European countries analysis. To test the hypothesis of research the cluster approach was applied, that allowed to divide investigated countries into 9 clusters. The study has concluded that countries with high level of human capital are characterized by a lower degree of inequality in income distribution. Correlation and regression analysis confirm the presence of feedback between the $\mathrm{HDI}$ and Gini index.
\end{abstract}

Keywords: human capital, inequality of income distribution, European countries, Gini index, human development index

\section{Introduction}

In any national economy, human capital is a leading factor of production, competitiveness maintaining and increasing. In the European Union markets competitiveness is considered in combination with increasing quality of life at the lowest possible unemployment rate. European countries don't differ greatly in human capital level, but its structure varies significantly in each countries. Income inequality is a barrier for economic growth and according to this indicator countries differ quite strongly. As an important factor, that can smooth population incomes out, a human capital, expenses for its creation, preservation and reproduction are marked. So, one of the human capital theory founders T. Schultz (1961) wrote that physical capital distribution is more uneven than human capital distribution, so with human capital stocks growth the declining of inequality in personal income distribution is taking place.

The role of human capital was described by G.Becker (1993), which proved that the persistent economic growth in the USA, Japan and Europe were related to investments in training scientific and technical personnel, that determines the growth of income per capita in the labor market. Chiswick B. (1974) showed that human capital, which was expressed in training costs and the returns on income, was one of the causes of regional differences.

\section{Methodology}

The purpose of the investigation is to analyze human capital role in the economic system. As an object of the study, 30 European countries were selected to examine human development index (HDI) and Gini index in them (data from Human Development Report 2013, 2014). The main hypothesis of the study is that countries with high human capital index are characterized by a lower value of Gini coefficient, that is, the countries with a higher level of human capital have a lower level of inequality.

Investigation methodology is based on cluster approach of international comparing. Wherein HDI includes estimation of four main welfare characteristics: life extension, health service level, education level, living conditions (GNI per capita). Analyzed countries are in groups with very high or high level of human capital comparing with other world countries. Gini measures the degree of inequality in the distribution of family income in a country. The subject of study is human capital level interrelation with economic inequality. Cluster analysis allows distinguishing common features and peculiarities of analyzing countries.

\section{Results}

The first cluster is represented by Slovakia for which relatively low HDI and Gini coefficient are specific (see Fig. 1). This 
country is among those with very high capital level, but it generally loses the rest ones and its indicator is below the average for the group. One can expect the growth of this indicator, as there is a number of positive trends: increase of life extension, GNI, education level. Between 1990 and 2012, Slovakia's HDI value has increased from 0.754 to 0.840 that is an increase of 11 percent or average annual increase of about 0.5 percent. According to the Gini coefficient Slovakia has one of the lowest level of inequality among the analyzing countries, however there are certain problems connected with rather high unemployment and low income levels around the country that prevent human capital growth. Kamasheva et al. (2013) investigation distinguished the main causes of inequity in labor market and discriminating groups that is actual for European countries.

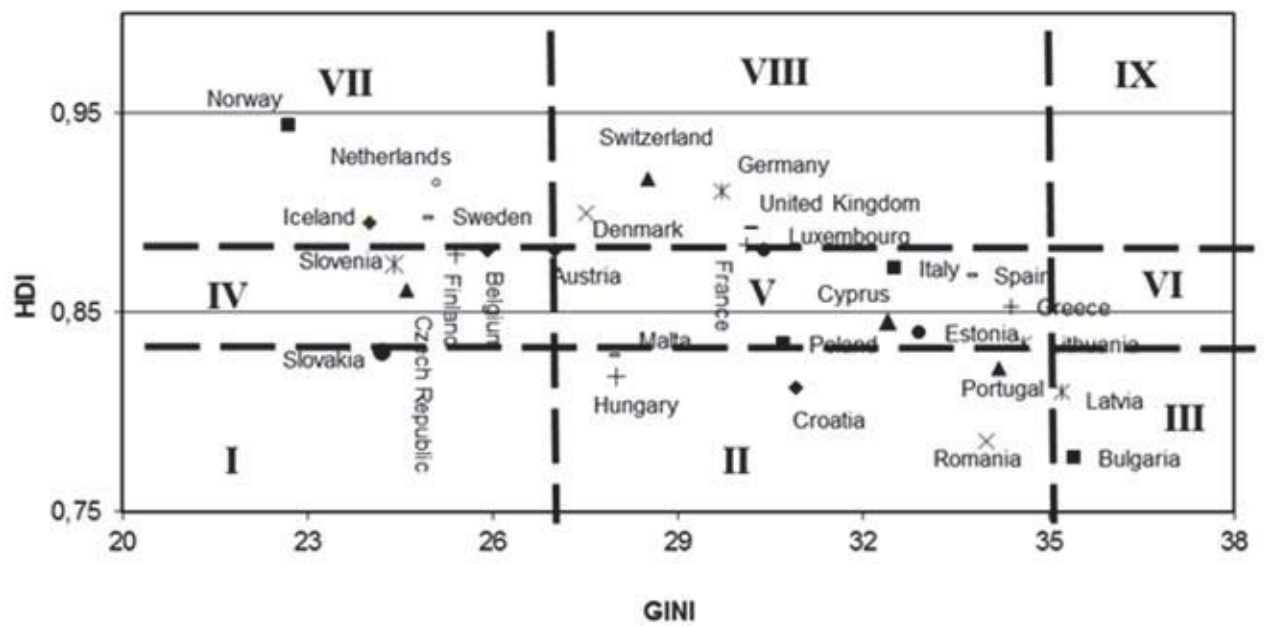

Figure 1. Results of cluster analysis

The second cluster unites countries with average Gini coefficient and low HDI: Croatia, Hungary and Malta. Index components tended to increase in Hungary and Malta. In Croatia there were fluctuations of GNI values, but since 2000 it has again begun to rise (16\%). Malta is the leader among these countries because of large GNI growth. Malta's GNI per capita has increased by about 88 percent between 1980 and 2012. Other indicators of the countries in this group are similar. The level of inequality in Hungary and Malta is roughly the same. In this cluster Croatia significantly stands out. In 2010, the coefficient had its maximum, then it has declined slightly, but it hasn't broken the mark of $30 \%$ yet.

The third cluster is Bulgaria, Latvia, Portugal, Romania. These countries reflect instability in economic development tendencies, strong dependence on the world market, internal economical problems. Countries with the lowest level of human capital and small GNI are in this group. Romania has a minimum value, in addition there is no growth of indicators related to education, and in 2013 this led to a decrease of human capital composite index. Bulgaria is the country with the highest level of income inequality among all investigated. It should be noted that there is no changing tendency for Gini coefficient. The coefficient was reducing from 1998 to 2002, but then in 2010 there was its significant growth to the maximum (0.36) after which there has been a slight decrease. In Romania an inequality can be explained by a combination of historical, social and economic factors. The transition to a market economy was accompanied by recessions, which increased the inequality. The main labour market characteristics in Romania are lower than the average in Europe. Latvia, like Bulgaria, is a country with one of the highest levels of income inequality in Europe and this level was increasing in 2004-2009. The disposable income of the richest $20 \%$ in Portugal (the 5th quintile group) is 5.6 times higher than the income of the poorest $20 \%$ (the 1 st quintile group). In Latvia the value of this inequality measure is 6.9. The index had been falling until 2009 , but after that it began to grow and this trend has remained.

The fourth cluster contains countries with medium HDI level and low GINI: Czech Republic, Slovenia, Finland, Belgium. Finland and Belgium have similar composition of index structure. In the both countries there is a positive dynamic in all components of the index, although the changes are not significant that can be explained by the high level of economic development. Czech Republic and Slovenia are a bit behind the countries mainly because of lower GNI levels. The growth of human capital with the continuing positive dynamics can be expected in this cluster. In Belgium Gini coefficient is one of the most stable in Europe, this can be explained by the economic policies: the minimum wage is at a high level, distribution policy is effective and tax level remains unchanged. The share of social expenditure in GDP isn't reducing. Slovenia is also characterized by stable and relatively low level of inequality. Furthermore, according to the 
OECD document, Slovenia was the most equal among the OECD countries at the international level in the late 2000s with a Gini coefficient of 0.24 and has managed to maintain this level of inequality. According to the Di Falco E. (2014) investigation, Norway and Slovenia had the lowest level of inequality (as measured by the Gini coefficient) in Europe in 2012, and that Spain and Latvia had the highest level. Czech Republic differs from the rest of the cluster. Because of the transition to the market system in the 90 s there was an increase of inequality, but by 2013 its rate had fallen to $24.6 \%$. The increased inequalities had an impact on household behavior in many aspects. The raising indebtedness, increased share of tertiary educated people or decreasing average number of household members to a certain extent have negatively affected the human capital. The rate of income inequality in Finland had been increasing during the period 1995-2000 afterwards it was stable on the level of 25\%. The main reason of behind growing income inequality was the increase of income among high income groups, which was mainly driven by increase in capital income.

The fifth cluster consists of countries with medium levels of human capital and income inequality. They are Austria, Poland, France, Luxembourg. Austria is characterized by a low level of inequality among developed countries and by the lowest rate in this group. Income inequality in France has followed a U-shaped curve over the period 1980-2010. During the 1970s and the 1980s, income inequality has decreased (by 15\%). Then, after a period of stability during the early 1990s, inequality started to rise. These changes relate mainly to the policies in wages and taxes. Since the mid-80s in Luxembourg high economic growth rate which led to the growth of living standards is observed. Though Luxembourg has one of the highest living standards for GDP per capita in the world, however, according to international standards the country belongs to the group of countries with relatively low levels of inequality. According to Fusco et all. (2013) the main reasons of increasing inequality in this country are associated with extension of labour market, increase of highly educated labour force share, institutional changes, social policy of income distribution.

The most numerous sixth cluster is formed by Lithuania, Italy, Cyprus, Estonia, Greece, Spain. On the one hand, in this group there are countries experiencing some financial difficulties at the state level (Italy, Greece, Spain). On the other hand Lithuania and Estonia belong to post-socialist countries in which for a long time economic equality policy had been led. According to Ballarino (2012) et al. study, state economical weakness is one of the causes of growing inequality in Italy, as ineffective state redistribution policy leads to income equality failure. Katsimi et al. (2012) study of shows that beginning from 2010 in Greece there has been reduce of GDP and of the minimum wage, which, combined with the cutting down of social policies spending has led to a reduction of inequality level possibly taking it back to the level it had three decades ago.

The Nordic countries Sweden, Norway, together with Netherlands, Iceland form the seventh cluster with low inequality and high HDI rates. These countries mostly confirm the hypothesis of an inverse relationship between human capital and inequality in the country. Salverda et al. (2013) study underlines the fact that in Netherlands despite of the slight increase of inequality the inequality of net equalized income of labour household has remained strikingly stable. Fritzell et al. (2012) note that income inequality in Sweden has increased substantially, especially from the mid-1990s and onwards.

The eighth cluster includes Denmark, Germany, the United Kingdom, and Switzerland with high human capital and middle inequality levels. According to Bjørnskov et al. research (2012), Danish income distribution has for very long been comparatively equally distributed. However, this was slowly changing towards a more unequal income distribution from the 1980s until 2010 years. Thus, Gini coefficient of disposable household income had increased from 25\% in the 1980s to around 30\% in 2006. McKnight and Tsang (2013) have concluded that the origins of modern inequality in the United Kingdom date back to the 1980 years. The main reasons of inequality changes, as in previous studies, scientists associate with the growing inequality on the labour market, social and tax policy of the state, demographic changes.

To the ninth cluster - countries with high values of HDI and Gini index - none of 30 analyzed countries was included. This result suggests the hypothesis that high level of human capital contributes lower inequality degree to be true.

The link between HDI and Gini index shows that the linear correlation coefficient between the selected indicators is $(-0.61)$, that indicates a feedback. The similar result is shown by a non-linear correlation coefficient of Spearman $(-0.61)$. At the same time regression analysis shows the highest value of determination for polinominal dependence of the sixth degree.

\section{Conclusion}

According to the study results it can be concluded that in investigating countries there are both common and multidirectional development trends. Thus in all the economies there is the growth of indicators forming HDI, that suggests an increasing role of human capital as a factor of socio-economic development, living standards and population 
welfare raising.

Trends in inequality level are not revealed as it is strictly affected by crisis. Regardless of inequality degree Gini coefficient in the country may be growing, stable or falling. The global economic crisis has influenced inequality, reducing its HDI in virtually all countries; especially it has concerned the developed countries, where it has led to the income loss of the richest. However, the main causes of inequality are differentiations of wages in different sectors of the economy and of employed and unemployed incomes, education level increase (which is directly related to human capital), tax and social policies of income redistribution and economic growth expressed in wealth.

Cluster analysis has allowed to distribute investigated countries into groups with similar values of HDI and Gini coefficient. To the ninth cluster with a high level of human capital and income inequality no country was included. The analyzed countries do not differ greatly in terms of human capital, as they all have its stable growth. The main difference is in the level of $\mathrm{GNI}$, which is higher in the developed European countries. The main components determining the degree of inequality are economic factors, as well as wage policy and taxes. Therefore, on the basis of cluster approach, it can be concluded that there is a relationship between the level of human capital and the degree of inequality in income distribution: among 30 investigated countries there was no one, in which high human capital level was combined with a high level of income distribution inequality. Correlation and regression analysis confirm the presence of feedback between the level of human capital and the degree of inequality in income distribution.

\section{References}

Ballarino G. et al. (2012). Growing Inequalities and Their Impacts in Italy. GINI Country Report for Italy. - September 2012. - 138 pp.

Becker G. (1993). Human Capital: a theoretical and empirical analysis, with special reference to education I Gary S. Becker. - 3rd ed. The University of Chicago Press.

Bjørnskov C., Neamtu I., Westergård-Nielsen N. (2012). Growing Inequalities and Their Impacts in Denmark. GINI Country Report for Denmark. - November 2012. - 116 pp.

Chiswick B. (1974). Income Inequality: Regional Analyses within a Human Capital Framework, National Bureau of Economic Research, Inc. $-197 \mathrm{pp}$.

Di Falco E. (2014). Income Inequality: nearly 40 per cent of total income goes to people belonging to highest (fifth) quintile. Statistics in focus, $12 / 2014$.

Fritzell J. et al. (2012). Growing Inequalities and Their Impacts in Sweden. GINI Country Report for Sweden. - December 2012. - 127 pp.

Fusco A. et al. (2013). Growing Inequalities and Their Impacts in Luxembourg. GINI Country Report. - April 2013. - 135 pp.

Shaidullin R.N., Ulesov D.V., Shigabieva A.M. and Safiullin L.N. Innovative Infrastructure in Post-Industrial Society/l World Applied Sciences Journal, 27(13), 2013, pp. 180-183.

Human Development Report 2013. The United Nations Development Programme. - Communications Development Incorporated, Washington DC. - $216 \mathrm{pp}$.

Kamasheva A., Kolesnikova J., Karasik E., Salyakhov E. (2013) Discrimination and Inequality in the Labor Market. Procedia Economics and Finance. - Vol. 5. - pp. 386-392.

Bulnina, I.S., Askhatova, L.I. Propositions and suggestions addressed to implement the provisions of the Russian federal law No 217. Mediterranean Journal of Social Sciences, Volume 5, Issue 18 SPEC. ISSUE, 2014, Pages 129-132

Katsimi M., Moutos T., Pagoulatos G., Sotiropoulos D. (2012). Growing Inequalities and Their Impacts in Greece. GINI Country Report for Greece. - April 2012. - 171 pp.

McKnight A., Tsang T. (2013). Growing Inequalities and Their Impacts in the United Kingdom. GINI Country Report for the United Kingdom. - July 2013. - $147 \mathrm{pp}$.

Safiullin L.N., Shaidullin R.N., Ulesov D.N., Shigabieva A.M. Essential features of small and medium business. Life Science Journal 2014; 11(6s): $392-395$.

Askhatova, L.I., Bulnina, I.S. Quality-of-life (QOL) improvement as a strategic resource of sustainable social and economic development of a region. Life Science Journal, Volume 11, Issue 6 SPEC. ISSUE, 2014, Pages 354-35.

Salverda W. et al. (2013). Growing Inequalities and Their Impacts in the Netherlands. GINI Country Report for the Netherlands. September 2013. - $199 \mathrm{pp}$.

Schultz T. (1961). Investment in Human Capital. The American Economic Review, Vol. 51, No. 1 (Mar., 1961), pp. 1-17. 